\title{
TENDÊNCIAS DE PESQUISAS RELACIONADAS AO PORTAL DA TRANSPARÊNCIA
}

\author{
Ricardo Cesar Silva \\ ricces2000@yahoo.com.br \\ Doutorando em Administração - UFSM \\ Gilnei Luiz de Moura \\ Doutor em Administração \\ mr.gmoura.ufsm@gmail.com \\ Marcelo Augusto Sapper de Souza \\ Mestre em Gestão de Organizações Públicas \\ sappersouza@hotmail.com \\ Adriana Camponogara Aires da Silva \\ Mestre em Letras \\ adrianaairesdasilva@hotmail.com \\ Sirlene Aparecida dos Santos \\ Mestre em Administração \\ Bibliotecária da Universidade Federal de Santa Mari \\ sirlenas2004@yahoo.com.br
}

\section{Resumo}

\begin{abstract}
Pressões dos cidadãos por melhores serviços e pelo devido emprego dos recursos públicos contribuem para a construção de ferramentas para que os gestores públicos prestem contas à sociedade e umas delas é o Portal da Transparência. Entretanto, a população tem dificuldades em compreender o conteúdo técnico, localização da informação no mesmo e, em muitos lugares, a dificuldade de acesso devido a baixa qualidade de infraestrutura de conexão da internet. Como objetivo, buscou-se identificar nas bases de dados de Teses e Dissertações - IBICT as tendências de pesquisas realizadas no Portal da Transparência. No que concerne à metodologia, indicou-se a classificação em categorias: título, assunto principal, unidade de análise e considerações finais. Para conclusão do trabalho, elencou-se como pontos positivos o alento de se buscar gastar com eficiência os recursos públicos, haja vista que estão publicados no Portal da Transparência e, de pontos negativos: dificuldade de encontrar as informações e interpretá-las e, muitas vezes, as mesmas, encontram-se incompletas. Para estudos futuros, com os elementos levantados, propõem-se a indicação de caminhos para a melhoria do Portal da Transparência.
\end{abstract}

Palavras Chave: Portal da Transparência. Controle Interno. Controle Social.

\section{INTRODUÇÃO}

Acontecimentos recentes no Brasil e no mundo reforçam ainda mais a necessidade de mecanismos de controle, cujo objetivo é a melhoria da gestão dos recursos públicos, por meio de serviços prestados com qualidade, sem desperdícios e buscando atender aos interesses e necessidades dos cidadãos, já que, de certa forma, são eles os mantenedores do Estado.

A pressão dos cidadãos por melhores serviços e pelo devido emprego dos recursos públicos também contribui para que os gestores públicos adotem uma postura mais ativa no sentido de criar meios, 
principalmente por meio de legislações e ferramentas, para o aperfeiçoamento da transparência e da prestação de contas, bem como para uma maior participação do cidadão na gestão pública, o que é chamado de controle social. Pascarelli Filho (2011) assinala que a sociedade brasileira está evoluindo no sentido de pressionar os gestores públicos quanto à prestação de contas e à qualidade dos gastos públicos.

O fato é que, segundo D'Avila e Oliveira (2002), os gestores estão reconhecendo a relevância dos controles internos nas organizações, quer com fins lucrativos ou não. Ao longo da história, atividades de controle interno vêm sendo enriquecidas por meio de novas legislações e iniciativas por parte dos entes da federação. Citam-se, como exemplos, a Lei 4.320 de 1964, o Decreto-Lei 200 de 1967, os princípios da Administração Pública, a Lei de Responsabilidade Fiscal, o Portal da Transparência e a Lei de Acesso à Informação. Essas iniciativas buscam tornar os gestores públicos mais responsáveis e cientes de suas responsabilidades.

No que concerne à tecnologia, o Setor Público, por meio de ferramentas oriundas do universo digital, busca promover maior transparência aos ritos e procedimentos ofertados aos usuários de produtos e serviços, fornecedores, credores, ou seja, a todos os seus stakeholders. Pascarelli Filho (2011) expõe que a Administração Pública, valendose da tecnologia, tem feito grande esforço no sentido de tornar-se mais transparente, criando condições mais favoráveis ao chamado controle social em relação a atos e fatos oriundos dos gestores públicos. Desse modo, esses instrumentos funcionam como um meio de publicidade dos órgãos públicos, cujo objetivo é demonstrar para a sociedade as diretrizes e políticas públicas realizadas e as por realizar, o valor gasto e as empresas envolvidas.

Nesse contexto, o Portal da Transparência, instituído por meio de iniciativa da Controladoria Geral da União (CGU), destaca-se como uma ferramenta que visa preencher as necessidades dos cidadãos quanto à prestação de contas, por meio da internet, a qual busca a participação da sociedade na gestão pública, permitindo que os cidadãos não só participem da formulação das políticas públicas, mas, também, fiscalizem de forma permanente a aplicação dos recursos públicos. No entanto, fatores como a falta de iniciativa da sociedade em relação à fiscalização, bem como possíveis deficiências das funcionalidades do Portal da Transparência, poderão dificultar a sua efetiva utilização por parte dos cidadãos (BRASIL, 2015c).

Objetiva-se analisar na Biblioteca Digital de Teses e Dissertações as tendências de pesquisa relacionadas ao Portal da Transparência, E os objetivos específicos consistem em:

- Detectar uma Base de Dados que contenha teses e dissertações disponíveis de acesso gratuito e conteúdo de cunho nacional;

- Identificar os conteúdos relacionados às iniciativas ligadas ao Portal da Transparência por meio da análise de teses e dissertações;

- Verificar as principais características e forma de utilização do Portal da Transparência por meio de pesquisa na Base de Dados - teses e dissertações;

- Estabelecer categorias e classificar as informações mais relevantes das dissertações e teses referentes aos assuntos, unidade federativa e considerações finais relacionadas ao Portal Transparência.

Portanto, de acordo com os pressupostos expostos, pretende-se fazer um estudo exploratório, por meio da análise de teses e dissertações, de como estão sendo percebidos os estudos relacionados ao Portal Transparência e a sua utilização.

\section{MECANISMOS DE CONTROLE INTERNO E PORTAL DA TRANSPARÊNCIA}

\subsection{MECANISMO DE CONTROLE INTERNO}

$\mathrm{Na}$ concepção de Hayashi, Sousa e Rothberg (2011), é papel das instituições, da sociedade civil organizada e dos cidadãos participar ativamente na esfera política, objetivando discutir e ter o direito de influenciar nas decisões sobre assuntos políticos. Desse modo, tendo em vista maiores pressões dos atores supracitados, os gestores públicos vêm buscando, 
constantemente, a adoção de políticas focadas no controle interno e na prestação de contas.

De acordo com Andrade e Amboni (2010), o controle interno está fundamentado no Artigo 70 da Constituição Federal de 1988, o qual determina que os poderes Executivo, Legislativo e Judiciário devem manter, de forma integrada, um sistema de controle interno. Para Souza e Borinelli (2012), o controle interno pode ser definido como uma ferramenta que visa garantir, com segurança, que a execução dos processos esteja ocorrendo conforme o planejado. Na visão de D'Avila e Oliveira (2002), tal controle reconhece que os seres humanos são passíveis de erros, ou melhor, nem sempre entendem, comunicam ou executam suas tarefas satisfatoriamente. A importância do referido controle é ressaltada por Andrade e Amboni (2012), os quais comentam que sem controle não é possível garantir a transparência da atividade administrativa e os objetivos constitucionais da república.

\subsubsection{Prestação de contas}

Em relação à prestação de contas, o controle social, espécie de controle interno, é conceituado por Alves, Becker e Silveira (2014) como um mecanismo de prevenção da corrupção, contribuindo para o correto emprego dos recursos públicos. Na definição apresentada na Cartilha sobre o controle social da CGU (2012), o controle social é sintetizado como a participação do cidadão na gestão pública, na prevenção da corrupção e no fortalecimento da cidadania. No Brasil, a preocupação em se estabelecer um controle social forte e atuante torna-se ainda maior, em razão da sua extensão territorial e do grande número de municípios que possui (Cartilha sobre controle social CGU 2012). Santos (2012) declara que a administração pública tem o compromisso de instrumentalizar e incentivar o controle social, por meio do fornecimento de informações que sejam compreensíveis e úteis aos cidadãos no ato de controlar e fiscalizar o uso dos recursos públicos pelos gestores. Desse modo, percebe-se o papel central da transparência na gestão dos recursos públicos.

Para Pascarelli Filho (2011), a transparência e a disponibilização de informações no setor público têm por finalidade enfrentar o problema da corrupção e propiciar o aperfeiçoamento constante das ações governamentais. Alves, Becker e Silveira (2014) afirmam que a ampliação da transparência, além de permitir um maior acesso dos cidadãos às informações da gestão pública, também aproxima o Estado da sociedade, o que é um requisito da boa governança. Nesse sentido, o Governo brasileiro acredita que a transparência é o melhor antídoto contra a corrupção, dado que ela é mais um mecanismo indutor de que os gestores públicos ajam com responsabilidade e permite que a sociedade, com informações, colabore com o controle das ações de seus governantes, no intuito de checar se os recursos públicos estão sendo usados como deveriam (BRASIL, 2015b). Corroborando o entendimento anterior, Pascarelli Filho (2011) destaca que a difusão da informação permitirá maiores oportunidades para o cidadão interagir na formulação e acompanhamento das políticas públicas, sendo possível aprimorá-las.

\subsubsection{Criação da GRU}

A criação da CGU pode ser considerada um avanço na busca do aperfeiçoamento da transparência e prestação de contas da administração pública brasileira. Pilagallo (2015) ressalta que, após a criação da CGU, órgão responsável pelo incremento da transparência pública, surgiu o Portal da Transparência, ferramenta que tem por finalidade divulgar detalhadamente os gastos federais realizados pelos órgãos e entidades da administração pública. Machado (2012) ressalta também que, por meio do Portal da Transparência, é possível a consulta sobre despesas, receitas, convênios, empresas sancionadas, valores repassados pelo governo federal aos governos estaduais e municipais, possibilitando ao cidadão colaborar, de forma anônima, com a fiscalização do uso do erário público. A Cartilha sobre o controle social da CGU (2012) destaca que, recorrendo ao Portal da Transparência, qualquer cidadão pode ser um fiscal da correta aplicação dos recursos públicos, sobretudo no que diz respeito às ações destinadas à sua comunidade.

Nesse contexto, Pascarelli Filho (2011) enfatiza que, mediante a tecnologia da informação, a administração pública brasileira vem aperfeiçoando seu processo de gestão, como é o caso do Portal da Transparência, o que tem resultado em ganhos quanto à 
transparência, agilidade e economia das ações governamentais. Um entendimento quanto ao Portal da Transparência, indicado por Brasília (2011), é que o cidadão bem informado tem melhores condições de conhecer e acessar outros direitos essenciais, como saúde, educação e benefícios sociais. Por este e por outros motivos, o acesso à informação pública tem sido, cada vez mais, reconhecido como um direito em várias partes do mundo.

Por outro lado, é importante ressaltar que as iniciativas do Portal da Transparência não atenderão, necessariamente, às prioridades dos cidadãos. Alves, Becker e Silveira (2014) comentam que, em alguns casos, ao invés dos órgãos públicos facilitarem o acesso às informações, funções que lhes é inerentes, estes criam barreiras a fim de não disponibilizar ou ofertar apenas parcialmente as informações. Nesse sentido, Pascarelli Filho (2011) ressalta que, quando há deliberada vontade de fraudar e esconder informações de interesse social, o princípio da publicidade, um dos pilares da administração pública, será o primeiro a sucumbir.

Diante do exposto anteriormente, a obtenção de uma relação satisfatória entre os gestores públicos e os cidadãos é alcançada quando a informação é apresentada de forma transparente e objetiva, com dados técnicos traduzidos para a linguagem cotidiana, cujo conteúdo é acessível para todos os cidadãos, inclusive às pessoas com deficiência. (BRASÍLIA, 2011). A ampliação da divulgação das ações governamentais a milhões de brasileiros, além de contribuir para o fortalecimento da democracia, prestigia e desenvolve as noções de cidadania. (BRASIL, 2015a).

\section{METODOLOGIA}

Nesta seção, é descrito o delineamento da pesquisa, bem como o método que serviu como norte de análise das informações, dados, ideias e resultados. O presente estudo apresenta características da pesquisa exploratória, a qual, segundo Gil (2010), busca proporcionar maior familiaridade com o problema, com o intuito de torná-lo mais explícito ou construir hipóteses.

Os dados foram coletados, no período de 22 de junho a 02 de julho de 2017, por meio do portal do Instituto Brasileiro de Informação em Ciência e Tecnologia (IBICT), o qual é depositário de todas as teses e dissertações nacionais, além das defendidas por brasileiros no exterior, os quais, porventura, solicitaram que fossem acrescentadas no portal. A base de dados utilizada para a realização da pesquisa foi a Biblioteca Digital de Teses e Dissertações (BDTD), a qual é aberta para o acesso dos usuários, de forma gratuita, e dispõe de mecanismos de busca simples - todas as partes do documento - e avançados - partes específicas do documento (resumo, autor, título, assunto). $\mathrm{O}$ mecanismo de busca utilizado foi o simples, com o termo "Portal da Transparência", tendo em vista que permite procurar e elencar todos os trabalhos relacionados ao tema, de forma exaustiva.

Após a coleta das teses e dissertações referentes ao assunto, foram identificadas e criadas categorias de análise com o objetivo de observar a tendência e as características no que compete ao tema "Portal da Transparência" e, dessa forma, o estado da arte da investigação em questão. Ressalta-se que a classificação e categorização dos assuntos serão dadas com as informações que advirem da coleta do Portal BDTD, e, por conseguinte, será analisado se a pesquisa é de âmbito da união, estados ou municípios; se é relacionada a um setor específico, a um ente específico ou a várias instituições; e se o material é utilizado para externalizar à transparência junto à sociedade. Observa-se que as teses e dissertações foram escolhidas por apresentarem bases teóricas aprofundadas, ratificadas pelos pares da academia, e também devido à padronização das partes (resumo, título, assunto, introdução, considerações finais ou conclusão), cujas características tornam as análises mais uniformes. Foram coletadas informações quanto às propostas das pesquisas, suas relações com o Portal da Transparência, resultados e limitações, as quais servirão como categorias de análise.

Além disso, serão criadas duas tabelas para coleta de dados, identificando-se o trabalho (título), o assunto, a unidade de análise, os resultados e as considerações finais. Assim, será possível traçar as tendências, além das dificuldades e facilidades que o Portal da Transparência apresenta, bem como se está atingindo seu objetivo fim de atender à sociedade no quesito de prestar informações rápidas, claras e objetivas. 
$\mathrm{Na}$ análise desses campos mencionados, serão observadas as tendências predominantes em relação aos assuntos abordados, às unidades federativas, e quais conclusões e considerações finais foram mais determinantes.

\section{RESULTADOS}

\subsection{TESES E DISSERTAÇÕES RECUPERADAS E TRABALHADAS}

Com base nos dados coletados, constatouse a recuperação de 19 trabalhos, dos quais, após a análise, sobraram 11 compatíveis com o tema da pesquisa.

No quadro 1, observam-se os títulos relacionados aos trabalhos, os assuntos principais, a unidade de análise e as considerações finais ou conclusões.

Quadro 1 - Detalhamento das informações inerentes a teses e dissertações.

\begin{tabular}{|c|c|c|c|}
\hline Título & $\begin{array}{l}\text { Assunto } \\
\text { Principal }\end{array}$ & Unidade & Considerações Finais ou Conclusão \\
\hline 1.Ler e navegar. & $\begin{array}{l}\text { Modo de } \\
\text { apresentação } \\
\text { e o conteúdo } \\
\text { do portal } \\
\text { transparência } \\
\text { do governo } \\
\text { federal. }\end{array}$ & União & $\begin{array}{l}\text { - Dificuldade dos leitores ao tentar encontrar as informações; } \\
\text { - A interação dos leitores e o Portal da Transparência devem ser } \\
\text { aperfeiçoadas; } \\
\text { - Falhas na composição visual, arquitetura da informação e tipo de } \\
\text { linguagem dificultam o acesso. }\end{array}$ \\
\hline $\begin{array}{l}\text { 2.Transparência } \\
\text { Pública e } \\
\text { Parlamento } \\
\text { Eletrônico. }\end{array}$ & $\begin{array}{l}\text { Discussão do } \\
\text { conceito de } \\
\text { transparência } \\
\text { pública, } \\
\text { aplicado à } \\
\text { comunicação } \\
\text { estatal, por } \\
\text { meio da } \\
\text { análise do } \\
\text { portal } \\
\text { eletrônico do } \\
\text { Senado } \\
\text { Federal }\end{array}$ & União & $\begin{array}{l}\text { - O Portal do Senado alcançou graus de transparência, atendendo mais } \\
\text { aos subprincípios da informação e da motivação em detrimento aos da } \\
\text { participação e interatividades cidadãs; } \\
\text { - O Senado disponibilizou uma grande quantidade de informações de } \\
\text { interesse público, mas a transparência ficou comprometida devido a } \\
\text { alguns fatores: as informações não são de fácil acesso, estão } \\
\text { disponibilizadas de forma fragmentada no Portal, os sistemas de } \\
\text { buscas não são confiáveis, conteúdos públicos com falta de } \\
\text { tempestividade. }\end{array}$ \\
\hline $\begin{array}{l}\text { 3.Informação } \\
\text { Pública como } \\
\text { instrumento de } \\
\text { controle social. }\end{array}$ & $\begin{array}{l}\text { Nível da } \\
\text { qualidade das } \\
\text { informações } \\
\text { disponibiliza } \\
\text { das nos } \\
\text { portais } \\
\text { transparência } \\
\text { dos } \\
\text { municípios } \\
\text { paraibanos. }\end{array}$ & Município & $\begin{array}{l}\text { - O nível da qualidade da informação e sua transparência são } \\
\text { relativamente baixos; } \\
\text { - Os governos disponibilizam poucas informações aos cidadãos, com } \\
\text { fraca interoperabilidade; } \\
\text { - Boa parte dos Portais possuem recursos tecnológicos satisfatórios, } \\
\text { com ferramentas de navegação e de busca de informações adequadas; } \\
\text { - Vários ajustes nos Portais de Transparência dos municípios são } \\
\text { necessários para que as informações possuam qualidade suficiente para } \\
\text { serem utilizadas a serviço do controle social. }\end{array}$ \\
\hline $\begin{array}{l}\text { 4.Um framework } \\
\text { para adaptação } \\
\text { de conteúdo e } \\
\text { navegação em } \\
\text { portais de } \\
\text { governo } \\
\text { eletrônico. }\end{array}$ & $\begin{array}{l}\text { Êxito dos } \\
\text { cidadãos nas } \\
\text { consultas ao } \\
\text { Portal da } \\
\text { Transparênci } \\
\text { a e as } \\
\text { eventuais } \\
\text { dificuldades } \\
\text { de }\end{array}$ & União & $\begin{array}{l}\text { - O desenvolvimento de portais do governo eletrônico, em especial } \\
\text { quando se trata de gastos públicos, deve obrigatoriamente permitir o } \\
\text { entendimento da informação pelos mais diversos públicos; } \\
\text { - Dificuldade para o cruzamento de dados entre os diversos gastos; } \\
\text { - Dificuldade de encontrar gastos relacionados às empresas estatais e } \\
\text { identificação de bens comprados com cartões de pagamento do } \\
\text { governo federal; } \\
\text { - Usuários comuns esperam encontrar as informações do Portal da } \\
\text { Transparência classificadas em tópicos completamente diferentes dos }\end{array}$ \\
\hline
\end{tabular}




\begin{tabular}{|c|c|c|c|}
\hline & $\begin{array}{l}\text { acessibilidad } \\
\text { e e } \\
\text { usabilidade } \\
\text { que podem } \\
\text { dificultar as } \\
\text { consultas. }\end{array}$ & & $\begin{array}{l}\text { existentes no Portal; } \\
\text { - Necessidade que o Portal disponha de informações referentes à } \\
\text { inclusão de gastos de diferentes hierarquias (Federal, Estadual e } \\
\text { Municipal) e poderes (Executivo, Legislativo e Judiciário) para que o } \\
\text { cidadão obtenha uma visão unificada dos gastos. }\end{array}$ \\
\hline $\begin{array}{l}\text { 5. Controle social } \\
\text { das políticas de } \\
\text { saúde. }\end{array}$ & $\begin{array}{l}\text { Exercício do } \\
\text { controle } \\
\text { social sobre } \\
\text { um agente } \\
\text { prestador de } \\
\text { serviços de } \\
\text { saúde } \\
\text { municipal. }\end{array}$ & Município & $\begin{array}{l}\text { - Apesar das formas de acesso às informações existentes e da } \\
\text { regulamentação do controle social, os governantes ainda precisam } \\
\text { melhorar a disponibilização de informação para que esta seja acessada } \\
\text { por toda sociedade e possa ser compreensível; } \\
\text { - A sociedade ainda caminha a passos lentos para uma cultura de maior } \\
\text { interferência e participação nas decisões políticas; talvez, esse seja o } \\
\text { maior problema para uma futura apropriação da sociedade pelo } \\
\text { controle social. }\end{array}$ \\
\hline $\begin{array}{l}\text { 6.Estratégia e } \\
\text { lobby. }\end{array}$ & $\begin{array}{l}\text { Consulta dos } \\
\text { contratos } \\
\text { públicos após } \\
\text { as eleições } \\
\text { por meio do } \\
\text { Portal da } \\
\text { Transparênci } \\
\text { a. }\end{array}$ & União & $\begin{array}{l}\text { - Os dados do Portal da Transparência são separados por tipo de } \\
\text { favorecido (entidade governamental, entidade sem fins lucrativos, } \\
\text { pessoas físicas e pessoas jurídicas), os quais são identificados pelo } \\
\text { número do CNPJ ou CPF. Para o caso das pessoas jurídicas, é possível } \\
\text { obter os dados por tipo de atividade econômica. }\end{array}$ \\
\hline $\begin{array}{l}\text { 7.Inteligência em } \\
\text { fontes abertas } \\
\text { para o suporte às } \\
\text { investigações de } \\
\text { indícios de } \\
\text { ilícitos na } \\
\text { importação de } \\
\text { mercadorias. }\end{array}$ & $\begin{array}{l}\text { Emprego de } \\
\text { bases } \\
\text { públicas para } \\
\text { auxiliar na } \\
\text { detecção de } \\
\text { indícios de } \\
\text { ilícitos. }\end{array}$ & União & $\begin{array}{l}\text { - Nos últimos anos, observa-se um aumento na tentativa de dar maior } \\
\text { transparência ao comércio exterior com a divulgação de informações } \\
\text { em portais públicos. Dessa forma, busca-se com a informação aberta à } \\
\text { sociedade o poder de contribuir com a detecção de irregularidades. }\end{array}$ \\
\hline $\begin{array}{l}\text { 8.E-gov e } \\
\text { comunicação. }\end{array}$ & $\begin{array}{l}\text { O governo } \\
\text { eletrônico } \\
\text { como meio } \\
\text { capaz de } \\
\text { condicionar } \\
\text { processos } \\
\text { comunicativo } \\
\text { s para criar, } \\
\text { coletar, } \\
\text { organizar e } \\
\text { compartilhar } \\
\text { informações } \\
\text { que podem } \\
\text { servir para a } \\
\text { tomada de } \\
\text { decisão. }\end{array}$ & Estadual & $\begin{array}{l}\text { O Portal segue a orientação de uma gestão transparente, voltada ao } \\
\text { interesse dos cidadãos, o qual conta com tecnologias para acompanhar } \\
\text { e fiscalizar as ações governamentais; }\end{array}$ \\
\hline $\begin{array}{l}\text { 9.Construindo a } \\
\text { accountabillity } \\
\text { em câmaras } \\
\text { municipais do } \\
\text { estado de Santa } \\
\text { Catarina. }\end{array}$ & $\begin{array}{l}\text { A capacidade } \\
\text { dos Portais } \\
\text { Eletrônicos } \\
\text { das câmaras } \\
\text { municipais } \\
\text { para a } \\
\text { construção da } \\
\text { accountabillit } \\
y\end{array}$ & Município & $\begin{array}{l}\text { - Os portais de transparência existem, mas sua presença parece atender } \\
\text { a um requisito da modernidade necessário para legitimar as câmaras } \\
\text { diante do padrão tecnológico dominante; } \\
\text { - A maioria dos portais analisados apresentou capacidade nula ou baixa } \\
\text { em possibilitar a construção de prestação de contas; } \\
\text { - Na observação dos indicadores do Modelo de Análise para a } \\
\text { prestação de contas, percebe-se que, na maioria dos portais, há uma } \\
\text { inexistência de qualquer tipo de demonstrativo e/ou impossibilidade de } \\
\text { sua localização, ou então os demonstrativos são divulgados }\end{array}$ \\
\hline
\end{tabular}




\begin{tabular}{|c|c|c|c|}
\hline & & & $\begin{array}{l}\text { parcialmente e/ou fora do prazo legal; } \\
\text { - A ausência de divulgação de relatórios simplificados dificulta o } \\
\text { entendimento e a acessibilidade às informações que procuram explicar } \\
\text { a gestão dos recursos públicos empreendida; } \\
\text { - O problema da não adequação e do não efetivo atendimento à Lei } \\
\text { pode ser explicado mais por componentes políticos históricos e de } \\
\text { cultura política do que técnicos; } \\
\text { - A construção de portais eletrônicos e o conteúdo que eles apresentam } \\
\text { também dependem da vontade dos atores que representam a instituição }\end{array}$ \\
\hline $\begin{array}{l}\text { 10.Governo } \\
\text { eletrônico nos } \\
\text { estados } \\
\text { federados } \\
\text { brasileiros }\end{array}$ & $\begin{array}{l}\text { Aspecto } \\
\text { interdisciplin } \\
\text { ar da política } \\
\text { governament } \\
\text { al e } \\
\text { estratégica de } \\
\text { e-GOV nos } \\
\text { websites dos } \\
\text { estados } \\
\text { federados } \\
\text { brasileiros }\end{array}$ & $\begin{array}{l}\text { Estados } \\
\text { Federados } \\
\text { brasileiros e } \\
\text { outros } \\
\text { países }\end{array}$ & $\begin{array}{l}\text {-Para alcançar resultados positivos no e-GOV estadual brasileiro é } \\
\text { essencial que o líder político tenha a percepção de que os websites } \\
\text { governamentais são uma extensão dos serviços da administração } \\
\text { pública, que engloba também a participação democrática direta; } \\
\text { - As políticas governamentais de e-GOV dos Estados Federados } \\
\text { Brasileiros, que correspondem aos serviços eletrônicos de interesse } \\
\text { público, com vistas a se desenvolver uma economia e cultura } \\
\text { orientadas ao ambiente digital, atendem parcialmente aos critérios } \\
\text { internacionais reconhecidos pela ONU e os métodos utilizados nos } \\
\text { EUA; } \\
\text { - O e-GOV é muito mais do que simplesmente a construção de } \\
\text { websites governamentais, pois é preciso ter a percepção de que não é } \\
\text { somente com tecnologia, pessoal especializado e injeção de capital em } \\
\text { projetos que se desenvolve um e-GOV. Para alcançar a eficiência, } \\
\text { transparência, visibilidade e qualidade plena no e-GOV, é necessária } \\
\text { uma ação indispensável em qualquer governo, a vontade política. }\end{array}$ \\
\hline $\begin{array}{l}\text { 11.A aplicação } \\
\text { das tecnologias } \\
\text { da informação e } \\
\text { comunicação } \\
\text { TICs na gestão } \\
\text { pública }\end{array}$ & $\begin{array}{l}\text { Investigar o } \\
\text { Governo } \\
\text { Eletrônico, e- } \\
\text { Gov, no } \\
\text { Brasil, por } \\
\text { meio do uso } \\
\text { das } \\
\text { Tecnologias } \\
\text { da } \\
\text { Informação e } \\
\text { da } \\
\text { Comunicação } \\
\text { TICs, mais } \\
\text { precisamente } \\
\text { da Internet. }\end{array}$ & $\begin{array}{l}\text { Estados } \\
\text { Federados } \\
\text { brasileiros }\end{array}$ & $\begin{array}{l}\text { Os itens Governança Eletrônica, Democracia Eletrônica, Informações e } \\
\text { Serviços Eletrônicos não são ofertados integralmente nos websites dos } \\
\text { estados brasileiros }\end{array}$ \\
\hline
\end{tabular}

Fonte: Elaborado pelos autores.

Diante das informações expostas, nota-se que os principais assuntos estão relacionados à Usabilidade e Acessibilidade do portal devido à dificuldade de acesso aos dados, à ocorrência de informações incompletas e termos técnicos, às investigações voltadas ao controle social da população e políticas públicas, além das práticas de E-gov, que procuram envolver e criar uma cultura no cidadão de uso de serviços diretos nos Portais Governamentais.

Em relação às unidades de análise, a União (Governo Federal) têm o maior número de trabalhos, 5, o que representa aproximadamente $45 \%$ do total, e os Estados e Municípios ficam empatados com 3 estudos cada, ou seja, $27,5 \%$ do total.

No que concerne às Conclusões e Considerações Finais, os trabalhos avaliaram que os Portais da Transparência são iniciativas positivas, mas que encontram dificuldades em externalizar a informação no formato palatável a seus usuários. Além disso, a composição visual e arquitetura da informação não são assimiláveis a um primeiro contato, uma vez que as interfaces não são intuitivas, e, muitas vezes, os sistemas de buscas não são confiáveis, e não 
existe a possibilidade de cruzamentos, como ocorre em sistemas de busca mais avançados.

Dessa forma, dificulta ao usuário o acesso às informações, que se apresentam dispersas, incompletas e incompreensíveis no Portal. Como prova disso, na maioria dos trabalhos pesquisados, os autores mencionaram o baixo nível na qualidade das informações, a falta de informações e a linguagem de difícil acesso à comunidade em geral (relatórios extensos, termos técnicos). Ressalta Alves, Becker e Silveira (2014) que, em alguns casos, ao invés dos órgãos públicos facilitarem o acesso às informações, funções que lhes é inerentes, estes criam barreiras a fim de não disponibilizá-las ou de disponibilizá-las apenas parcialmente.

Para tanto, em vez de aproximar a sociedade para que ocorra o controle social e a transparência das ações, o governo oferta e divulga a ferramenta como uma peça publicitária para acesso de poucos, pois somente o "suprassumo" relacionado ao governo conhece a fundo as informações técnicas extensas e de difícil entendimento. Santos (2012) enfatiza qual deve ser o papel da administração pública e seu compromisso de instrumentalizar e incentivar o controle social, por meio do fornecimento de informações que sejam compreensíveis e úteis aos cidadãos no ato de controlar e fiscalizar o uso dos recursos públicos pelos gestores.

\subsection{ASSUNTOS ABORDADOS}

A seguir mostra-se a descrição e síntese dos principais assuntos abordados, as unidades de abrangência do estudo, os resultados e as considerações finais, detalhando-se os aspectos positivos, as deficiências, as melhorias, as análises e as recomendações.

Assuntos abordados com relação ao tema Portal da Transparência, as teses e dissertações focam nos seguintes assuntos: Conteúdo e qualidade das informações; Acessibilidade e linguagem das informações; Portal da Transparência como instrumento de controle social e prestação de contas e Influência de fatores institucionais e externos na apresentação das informações.

As Unidades de Análise são: Poder Executivo; Poder Legislativo; Poder Judiciário; Nível Federal; Nível Estadual e Nível Municipal.
A seguir observa-se as principais considerações e resultados das teses e dissertações analisadas:

\subsubsection{Análises Positivas:}

O Portal do Senado alcançou graus de transparência, atendendo mais aos subprincípios da informação e da motivação em detrimento dos da participação e interatividades cidadãs.

Percebeu-se que boa parte dos Portais possuem recursos tecnológicos satisfatórios, com ferramentas de navegação e de busca de informações adequadas.

Outro ponto positivo foi os dados do Portal da Transparência que são separados por tipo de favorecido (entidade governamental, entidade sem fins lucrativos, pessoas físicas e pessoas jurídicas), os quais são identificados pelo número do CNPJ ou CPF. Para o caso das pessoas jurídicas, é possível obter os dados por tipo de atividade econômica.

Nos últimos anos, observa-se uma maior tentativa de se dar maior transparência ao comércio exterior com a divulgação de informações em portais públicos. Dessa forma, busca-se com a informação aberta dar à sociedade o poder de contribuir com a detecção de irregularidades, ainda observouse que o Portal segue a orientação de uma gestão transparente, voltada ao interesse dos cidadãos, que conta com tecnologias para acompanhar e fiscalizar as ações governamentais.

\subsubsection{Deficiências e possibilidades de melhoria}

Elencamos a seguir algumas dificuldades encontradas ao acessar o Portal da Transparência: dificuldade dos leitores ao tentarem encontrar as informações; Falhas na composição visual, arquitetura da informação e tipo de linguagem dificultam o acesso; $\mathrm{O}$ Senado disponibilizou uma grande quantidade de informações de interesse público, mas a transparência ficou comprometida devido a alguns fatores: as informações não são de fácil acesso, estão disponibilizadas de forma fragmentada no Portal, os sistemas de buscas não são confiáveis, conteúdos públicos com falta de tempestividade.

Percebe-se ainda que o nível da qualidade da informação e sua transparência são relativamente baixos; Os governos disponibilizam poucas informações aos 
cidadãos, com fraca interoperabilidade; Complicação para o cruzamento de dados entre os diversos gastos; Dificuldade de se encontrar gastos relacionados às empresas estatais e identificação de bens comprados com cartões de pagamento do governo federal.

Na observação dos indicadores do Modelo de Análise para a prestação de contas, percebe-se que, na maioria dos portais, há uma inexistência de qualquer tipo de demonstrativo e/ou impossibilidade de sua localização ou, então, os demonstrativos são divulgados parcialmente e/ou fora do prazo legal.

A ausência de divulgação de relatórios simplificados dificulta o entendimento e a acessibilidade às informações que procuram explicar a gestão dos recursos públicos empreendida; As políticas governamentais de e-GOV dos Estados Federados Brasileiros, que correspondem aos serviços eletrônicos de interesse público, com vistas a se desenvolver uma economia e cultura orientadas ao ambiente digital, atendem parcialmente aos critérios internacionais reconhecidos pela ONU e os métodos utilizados nos EUA;

Os itens Governança Eletrônica, Democracia Eletrônica, Informações e Serviços Eletrônicos não são ofertados integralmente nos websites dos estados brasileiros.

\subsubsection{Análises e recomendações}

Chega-se a um consenso de que a interação dos leitores e o Portal da Transparência devem ser aperfeiçoados; Vários ajustes nos Portais de Transparência dos municípios são necessários para que as informações possuam qualidade suficiente para serem utilizadas a serviço do controle social.

O desenvolvimento de portais do governo eletrônico, em especial quando se trata de gastos públicos, deve obrigatoriamente permitir o entendimento da informação pelos mais diversos públicos; Usuários comuns esperam encontrar as informações do Portal da Transparência classificadas em tópicos completamente diferentes dos existentes no Portal.

Observou-se a necessidade que o Portal disponha informações referentes a inclusão de gastos de diferentes hierarquias (Federal, Estadual e Municipal) e poderes (Executivo,
Legislativo e Judiciário) para que o cidadão obtenha uma visão unificada dos gastos; Apesar das formas de acesso às informações existentes e da regulamentação do controle social, os governantes ainda precisam melhorar a disponibilização de informação, para que esta seja acessada por toda sociedade e possa ser compreensível;

A sociedade ainda caminha a passos lentos para uma cultura de maior interferência e participação nas decisões políticas; talvez, esse seja o maior problema para uma futura apropriação da sociedade pelo controle social;

A instituição pública sofreu influência de fatores externos - na forma de pressões coercitivas, normativas e miméticas - na sua estrutura de Governança de TI, para implementação do e-serviço analisado, ou seja, na implantação de uma prática de governança eletrônica;

É possível perceber a importância do ambiente, através de fatores institucionais, no condicionamento organizacional e a influência que exerce na tomada de decisão para implementação de práticas de governança eletrônica nas organizações; Os portais de transparência existem, mas sua presença parece atender a um requisito da modernidade necessário para legitimar as câmaras diante do padrão tecnológico dominante; A maioria dos portais analisados apresentou capacidade nula ou baixa em possibilitar a construção de prestação de contas.

O problema da não adequação e do não efetivo atendimento à Lei pode ser explicado mais por componentes políticos históricos e de cultura política do que técnicos; A construção de portais eletrônicos e o conteúdo que eles apresentam também dependem da vontade dos atores que representam a instituição;

Para alcançar resultados positivos no eGOV estadual brasileiro, é essencial que o líder político tenha a percepção de que os websites governamentais são uma extensão dos serviços da administração pública, que engloba também a participação democrática direta;

O e-GOV é muito mais do que simplesmente a construção de websites governamentais, pois é preciso ter a percepção de que não é somente com tecnologia, pessoal especializado e injeção de capital em projetos que se desenvolve um e- 
GOV. Para alcançar a eficiência, transparência, visibilidade e qualidade plena no e-GOV, é necessária uma ação indispensável em qualquer governo, a vontade política.

\section{CONSIDERAÇÕES FINAIS}

Este trabalho procurou contribuir no estudo do Portal da Transparência, por meio de uma pesquisa em teses e dissertações sobre o tema, nas quais foi possível observar pontos positivos, negativos e recomendações sobre a sua utilização por parte da sociedade.

Quanto aos aspectos positivos, percebe-se que o referido portal representa um novo estímulo para fins de maior transparência dos gastos públicos e para um efetivo controle social dos cidadãos brasileiros.

No que diz respeito aos aspectos negativos, ou de maneira mais branda, das necessidades de melhoria, fica evidente a necessidade de aperfeiçoamentos no Portal da Transparência no que se refere às dificuldades do cidadão de encontrar e entender as informações, de algumas vezes as mesmas serem intempestivas e incompletas, e, também, tendo em vista a falta de flexibilidade dos dados apresentados, o que prejudica a análise por parte dos cidadãos.

Nesse sentido, apesar das possibilidades de aperfeiçoamento do referido portal, não podemos deixar de destacar a sua relevância para a sociedade brasileira. Trata-se de uma ferramenta que exerce uma forte pressão sobre os gestores públicos, os quais, pelo menos em teoria, terão suas despesas expostas à sociedade, exigindo dos mesmos critérios mais coerentes para a utilização do erário público. No que diz respeito à sociedade, não podemos esquecer sua relevância no processo do controle social. Dessa forma, o país necessita de cidadãos que realmente entendam e participem ativamente do processo de fiscalização e controle dos gastos públicos, o que, consequentemente, refletirá em menos desperdícios e maior satisfação da população.

Para estudos futuros, com os elementos levantados, propõem-se a indicação de caminhos para a melhoria do Portal da Transparência.

\section{RESEARCH TRENDS RELATED TO THE TRANSPARENCY PORTAL}

\section{ABSTRACT}

The pressure of citizens for better services and the due use of public resources contribute to building tools for public managers render accounts to the society, being the Transparency Portal one of those. However, the population has difficulties in understanding the technical content and to locate the information in the Portal. Moreover, in many places, it is difficult to gain access due to the low quality of the Internet connection infrastructure. As an objective, we sought to identify, in the databases of Theses and Dissertations - IBICT, the trends of research carried out in the Transparency Portal. With regard the methodology, the classification was indicated in categories: title, main matter, unit of analysis and final considerations. To conclude the work, were listed as a positive point the stimulus to seek the efficient spending of public resources because they are published in the Transparency Portal, and as negative points the difficulty of finding information and interpreting them, as well as the incomplete information, which occurs in many cases. For future studies, with the elements raised, it is proposed to indicate ways to improve the Transparency Portal.

Keywords: Transparency Portal, Internal control, Social Control.

\section{REFERÊNCIAS}

ALBUQUERQUE, E. F. Informação
Pública como Instrumento de Controle
Social: o Nível de Qualidade da Informação Disponível nos Portais da Transparência dos Municípios Paraibanos. 2013. 100 f.

Dissertação (Mestrado) - Curso de Mestrado 
Profissional em Gestão em Organizações Aprendentes, Universidade Federal da Paraíba, João Pessoa, 2013. Disponível em: <www.ufpb.br〉. Acesso em: 22 jun. 2015.

ALVES, F. D; BECKER, F. de O; SILVEIRA, S. G. (Org.). A Administração Pública Municipal e os desafios contemporâneos. São Paulo: Perse, 2014.

ANDRADE, R. O. B. de; AMBONI, N. Estratégias de Gestão: processos e funções do administrador. Rio de Janeiro: Elsevier, 2010.

AZEVEDO, R. S. de. Ler e navegar.gov.br: experiências de interação em um portal de transparência. 2013. 122 f. Dissertação (Mestrado) - Curso de Contabilidade, Universidade Federal de Minas Gerais, Belo Horizonte, 2013. Disponível em: $<$ http://www.bibliotecadigital.ufmg.br/dspace/ handle/1843/MGSS-9B3PEA?show=full>. Acesso em: 22 jun. 2015.

\section{BARBOSA, H. Transparência Pública e}

Parlamento: A reforma do Poder Judiciário no portal do Senado Federal 2000-2004. 2009. 100 f. Tese (Doutorado) - Curso de Comunicação Social, Universidade Metodista de São Paulo, São Paulo, 2009. Disponível em: <www.metodista.br>. Acesso em: 22 jun. 2015.

BRASIL. Presidência da República. Controladoria Geral da União. Controle Social. 2015c. Disponível em: < http://transparencia.gov.br/controleSocial/>. Acesso em: 22 jun. 2015.

BRASIL. Presidência da República. Controladoria Geral da União. Páginas de Transparência Pública. 2015a. Disponível em:

$<$ http://www3.transparencia.gov.br/Transpare nciaPublica/>. Acesso em: 22 jun. 2015.

BRASIL. Presidência da República. Controladoria Geral da União. Sobre o Portal. 2015b. Disponível em: <http://www3.transparencia.gov.br/sobre/>. Acesso em: 22 jun. 2015. introdução à Lei $\mathrm{n}^{\circ} 12.527$, de 18 de novembro de 2011. Brasília: CGU, 2011. 25 p. Disponível em:

<http://www.acessoainformacao.gov.br/centra 1-de-

conteudo/publicacoes/arquivos/cartilhaacesso ainformacao.pdf>. Acesso em: 22 jun. 2015.

\section{CALBO, É. R. Inteligência em fontes} abertas para suporte às investigações de indícios de ilícitos na importação de mercadorias: um estudo em bases abertas de comércio exterior. 2012. 100 f. Dissertação (Mestrado) - Curso de Ciência da Informação, Universidade Católica de Brasília, Brasília, 2012. Disponível em: <www.ucb.br>. Acesso em: 22 jun. 2015.

CHAGAS, L. S. Estratégia e lobby: uma análise da interação entre grupos econômicos e contribuições de campanha. 2014. $132 \mathrm{f}$. Dissertação (Mestrado) - Curso de Economia, Universidade de São Paulo, São Paulo, 2014. Disponível em: <http://www.teses.usp.br/teses/disponiveis/12 /12138/tde-05032015-194503/pt-br.php>. Acesso em: 22 jun. 2015.

\section{COELHO, J. C. E- Gov e Comunicação:} estudo do portal da Prefeitura de Juiz de Fora. 2009. 122 f. Dissertação (Mestrado) - Curso de Comunicação e Sociedade-tecnologias da Comunicação, Universidade Federal Fluminense, Juiz de Fora, 2009. Disponível em: <www.ufjf.br>. Acesso em: 22 jun. 2015.

D'AVILA, M. Z.; OLIVEIRA, M. A. M de. Conceitos e técnicas de controles internos de organizações. São Paulo: Nobel, 2002.

DEUS, E. S. de. Controle social das políticas de saúde: o caso do Instituto Municipal de Estratégia de Saúde da Família. 2013. 120 f. Dissertação (Mestrado) - Curso de Administração, Políticas Públicas, Pontifícia Universidade Católica, Porto Alegre, 2013. Disponível em: <www.pucrs.br>. Acesso em: 22 jun. 2015.

FREIRE, E. Ética na administração Pública: teoria e 640 questões. 3. ed. rev. atual. Rio de Janeiro: Elsevier, 2006.

BRASIL. Controladoria-Geral da União.

Acesso à Informação Pública: Uma 
FREIRE, E. Ética na administração Pública: teoria e 640 questões. 3. ed. Elsevier: Rio de Janeiro, 2006.

GIL, Antônio Carlos. Como elaborar projetos de pesquisa. 4. ed. São Paulo: Atlas, 2008.

HAYASHI, M.; SOUSA, C.; ROTHBERG, D. Apropriação social da ciência e tecnologia: contribuições para uma agenda. Campina Grande: EDUEPB, 2011.

IBICT. Biblioteca Digital de Teses e Dissertações. 2015. Disponível em: <http://www.ibict.br/sobre-oibict/apresentacao>. Acesso em: 22 jun. 2015.

MACHADO, C. J. S. (Org.). Ciências, Políticas Públicas e sociedade sustentável. Rio de Janeiro: E-papers, 2012.

MAGALHÃES, D. M. B. A aplicação das tecnologias da informação e da comunicação TICs, na gestão pública: um estudo sobre o governo eletrônico no Brasil. 2008. $111 \mathrm{f}$.

Dissertação (Mestrado) - Curso de Administração Pública, Fundação João Pinheiro, Belo Horizonte, 2008. Disponível em: <www.fjp.mg.gov.br>. Acesso em: 22 jun. 2015.

MARQUES, C. de A. Controle dos contratos administrativos: caminho para a transparência pública, controle social e accountability. 2012. 121 f. Dissertação (Mestrado) - Curso de Administração, Centro de Ciências da Administração e Socioeconômicas - ESAG, Universidade do Estado de Santa Catarina, Florianópolis, 2012. Disponível em: $<$ http://www.tede.udesc.br/tde_busca/arquivo. php? codArquivo=2829>. Acesso em: 22 jun. 2015.

PALUDO, A. V. Administração Pública: teoria e questões: Rio de Janeiro: Elsevier, 2010.

PASCARELLI FILHO, M. A nova

Administração Pública: profissionalização, eficiência e governança. São Paulo: DVS, 2011.

PILAGALLO, O. Ética concorrencial: como o ETCO introduziu essa luta na agenda nacional em 10 anos. Rio de Janeiro: Elsevier, 2015.

RECH, D. (Coord.). Direitos Humanos no Brasil: diagnóstico e perspectivas. Rio de Janeiro: Ceris, 2003.

SANTOS, F. Contabilidade Pública. Recife: Clube de Autores, 2012.

\section{SILVA, R. C. Governo Eletrônico nos}

Estados Federados Brasileiros. 2013. 145 f.

Dissertação (Mestrado) - Curso de Direito,

Unisantos, Santos, 2013. Disponível em: 〈www.unisantos.br〉. Acesso em: 22 jun. 2015.

SOUZA, B. C. Controladoria. Curitiba: IESDE Brasil, 2012.

VIANA, G. B. Um framework para adaptação de conteúdo e navegação em portais de governo eletrônico. 2012. $200 \mathrm{f}$. Tese (Doutorado) - Curso de Programa De pós-graduação em Ciência da Computação, Instituto de Computação, Universidade de Campinas, Campinas, 2012. Disponível em: <http://www.bibliotecadigital.unicamp.br/doc ument/?code $=000897108>$. Acesso em: 22 jun. 2015. 